\title{
Assembling an ant community: species functional traits reflect environmental filtering
}

\author{
Philipp T. Wiescher · Jessica M. C. Pearce-Duvet • \\ Donald H. Feener
}

\begin{abstract}
Species should only persist in local communities if they have functional traits that are compatible with habitat-specific environmental conditions. Consequently, pronounced regional environmental gradients should produce environmental filtering, or a trait-based spatial segregation of species. It is critical to quantify the links between species' functional traits and their environment in order to reveal the relative importance of this process to community assembly and promote understanding of the impacts of ongoing environmental changes. We investigated this relationship using epigaeic ants in an environmentally heterogeneous region of Florida. We found evidence for environmental filtering as environmental conditions such as groundcover, surface temperature, vapor pressure deficit, and plant diversity were strongly correlated with assemblage composition. Certain species traits appeared particularly important to persistence: (1) ants in environments with less groundcover have relatively longer legs but do not differ in size, (2) ants in hotter environments exhibit greater thermal tolerances, and (3) ants in hotter and drier environments do not exhibit greater desiccation resistance. These
\end{abstract}

P. T. Wiescher $(\square)$ · J. M. C. Pearce-Duvet · D. H. Feener Department of Biology, University of Utah, 257 South 1400 East, Salt Lake City, UT 84112, USA

e-mail: p.wiescher@utah.edu

D. H. Feener

e-mail: donald.feener@utah.edu

J. M. C. Pearce-Duvet

Estación Biológica de Doñana, CSIC,

c/Americo Vespucio s/n, 41092 Sevilla, Spain

e-mail: jmcolette.pearce@gmail.com findings show surface complexity and temperature may interact with morphology and physiology to impact the spatial distribution of ants and underscore the importance of climate change. Climate warming is predicted to alter assemblage composition, competitive dynamics, and consequently impact ecosystem processes. We suggest environmental filters acting at regional scales, as shown here, act in tandem with more frequently studied local-scale competitive interactions to delimit ant community assemblages.

Keywords Ants (Formicidae) · Community assembly · Size-grain hypothesis $\cdot$ Stress tolerance $\cdot$ Trait-environment links

\section{Introduction}

It has long been observed that assemblages of species found in different habitats are different. However, identifying the mechanisms underlying this pattern, the why and how of assemblage composition, remains a central challenge in ecology (Agrawal et al. 2007; McGill et al. 2006). It has been hypothesized that environmental conditions may filter species: species arriving from the regional species pool only persist in local habitats if functional physiological, morphological, and/or life-history traits are compatible with habitat characteristics (Keddy 1992; Southwood 1988). A range of other processes (e.g., competition, predation) can also generate patterns of species segregation along environmental gradients (Englund et al. 2009; Gotelli and McCabe 2002; Hausdorf and Hennig 2007), and multiple processes may operate simultaneously (Englund et al. 2009). As a result, quantifying the links between a habitat's conditions and the functional traits of its species represents a first, necessary step in determining the processes governing 
species distributions. Investigations of trait-environment links are also important because they inform theoretical advances, enhance understanding of ecosystem functioning, and, perhaps most importantly, enable predictions of how environmental changes can alter assemblage composition (Green et al. 2008; Lavorel and Garnier 2002; Lebrija-Trejos et al. 2010; McGill et al. 2006; Menezes et al. 2010; Webb et al. 2010; Weiher and Keddy 1999).

Ant assemblages provide an ideal study system for examining trait-environment relationships as they commonly vary in composition along environmental gradients (Gotelli and Ellison 2002; Hill et al. 2008; Spiesman and Cumming 2008; van Ingen et al. 2008). The role of environmental filtering in this pattern is supported by findings showing that some individual ant species have specific traits that correlate with environmental conditions (e.g., Hölldobler and Wilson 1990; Menke and Holway 2006; Schilman et al. 2007). However, because these relationships have not been assessed for the community at large, it is difficult to say whether filtering only affects certain species or if it may have a broader relevance by acting at the scale of the community. Identifying how ant traits are linked with environmental conditions is a necessary step in assessing how ongoing environmental changes such as climate warming may alter ant assemblages and ecosystem processes coupled with ant diversity (Folgarait 1998).

This study addresses these considerations by examining the relationship between habitat conditions, species occurrences, and species' functional traits in an epigaeic ant assemblage spanning four habitat types in central Florida. We focus on environmental factors previously hypothesized to affect ant distributions: ground surface complexity, temperature, and vapor pressure deficit (VPD; a composite measure of temperature and relative humidity) (Hölldobler and Wilson 1990; Kaspari 1993; Kaspari and Weiser 1999, 2000). These factors may be linked to ant traits in the following ways. First, the size-grain hypothesis posits surface complexity drives an allometric relationship between ant size and leg length, with larger ants having proportionally longer legs than smaller ants (Kaspari and Weiser 1999; Parr et al. 2003). This relationship may be a consequence of how ants move through their environment: smaller, shorterlegged ants more successfully forage through the leaf-litter while larger ants forage across it, as longer legs can enable faster or more efficient movement (Farji-Brener et al. 2004; Pearce-Duvet et al. 2011a). As a result, ant assemblages in comparatively low surface complexity environments are expected to contain species of larger sizes and greater relative leg lengths (Parr et al. 2003; Sarty et al. 2006). A study comparing ant body sizes across savanna habitats of contrasting surface complexity in Africa found minimal support for this prediction (Parr et al. 2003), although further evidence is needed to assess the generality of this pattern.
Second, as small-bodied ectotherms, heat and water stress in ants are strongly coupled with environmental conditions but are also affected by physiological, morphological, and/ or behavioral traits (Cerdá 2001; Doblas-Miranda and Reyes-Lopez 2008; Hood and Tschinkel 1990; Schilman et al. 2007). Individual species that occur in extreme temperature and/or VPD conditions can exhibit enhanced thermal tolerance and desiccation resistance and, within local assemblages, these traits can differ dramatically between species (Bestelmeyer 2000; Cerdá et al. 1998a; Hood and Tschinkel 1990; Schilman et al. 2007; Wittman et al. 2010). However, it is unclear if these traits scale up to impact ant community assembly along temperature or VPD gradients.

Based on these observations, we make several predictions. If the environmental conditions discussed here are filtering ant species, and thus shaping local ant assemblages, we predict that: (1) low surface complexity environments will contain larger and relatively longer-legged species, (2) environments with higher mean daytime temperatures will contain more thermally tolerant species, and (3) environments with greater mean daytime VPDs will contain more desiccation-resistant ants.

\section{Materials and methods}

Study system and sites

Archbold Biological Station is a 2,101-ha ecological reserve located at the southern end of the Lake Wales Ridge in Highlands County, central Florida (Abrahamson 1984). Archbold encompasses one of the largest natural tracts of southern ridge vegetation and contains pristine examples of all the original upland habitats found along the Lake Wales Ridge. The primary natural terrestrial habitats ( $\sim 87 \%$ of the total area) are interspersed in a spatial mosaic and include Flatwoods (FL), Sand Pine Scrub (SP), Scrubby Flatwoods (SF), and Southern Ridge Sandhill (SR). SP and SF habitats tend to be relatively open and shrubby, while FL and SR are more forested and feature varying amounts of canopy cover and large trees (Abrahamson 1984; Menges et al. 1993). While the ant fauna of Archbold has been rigorously surveyed (Deyrup and Trager 1986), our present work represents an attempt to clarify the processes underlying patterns of ant distributions in this area.

We established three long-term plots in each of the four habitats, for a total of 12 plots. We situated plots on different habitat islands to minimize spatial auto-correlation and at least $10 \mathrm{~m}$ from the nearest differing habitat. Plots were $40 \mathrm{~m} \times 40 \mathrm{~m}$ and consisted of 16 stations separated by $10 \mathrm{~m}$ in a $4 \times 4$ array. The plot establishment was modified in the SR habitat because of its extremely dense vegetation. 
First, sites were selected based on accessibility, which resulted in the three plots being located on the same habitat island and relatively close to each other. Second, the stations of two of the plots were not situated in a $4 \times 4$ array, although station number (16) and station separation distance $(10 \mathrm{~m})$ were maintained.

To determine the environmental characteristics of the four habitats, we first measured groundcover, surface temperature, ambient temperature, and relative humidity. To estimate groundcover, we placed $0.25-\mathrm{m}^{2}$ grids divided into $0.01-\mathrm{m}^{2}$ squares centered over each station on each plot in 2008. The total amount of covered ground was recorded; values were averaged to determine percent groundcover for each habitat. To measure surface temperature, we placed a HOBO@ Type K thermocouple data logger (Onset) at the center of a plot representative of each habitat type. We calculated the average daytime (0600-1800 hours) surface temperatures for the summers of 2007 and 2008. We placed HOBO $\odot$ Pro series RH Temp data loggers (Onset) at the center of the representative plots to record ambient temperature and relative humidity; loggers were situated $50 \mathrm{~cm}$ above the soil surface. Average daytime (0600-1800 hours) ambient temperature $(T)$ and percent relative humidity $(\mathrm{RH})$ for the summers of 2006, 2007, and 2008 were used to calculate average vapor pressure deficit (VPD) for each habitat, where vapor pressure $(\mathrm{VP})=512+73.662 \times T-0.72645 \times$ $T^{2}+0.079616 \times T^{3}$ and VPD $(\mathrm{kPa})=V P-(\mathrm{VP} \times \mathrm{RH} \times$ $100^{-1}$ ) (Ward and Elliot 1995). In addition, percent soil moisture at $0-20 \mathrm{~cm}$ of depth, soil $\mathrm{pH}$, plant species richness (Abrahamson 1984; Menges and Gallo 1991), and time since fire (J. Layne, R. Myers, E. Menges, and K. Main, unpublished data) for each habitat were identified using existing data sources.

\section{Ant sampling methodology}

We censused plots for ants in the summers of 2006, 2007, and 2008; ant activity is greatest during this time (M. Deyrup, personal communication). We employed a combination of pitfall traps and leaf-litter sampling as these methods effectively characterize diverse epigaeic ant assemblages (Bestelmeyer et al. 2000). We set pitfall traps at eight randomly selected stations per plot for a 72 -h period between May and June in all 3 years. The same stations were sampled each year. This resulted in 24 traps per habitat type ( 8 stations $\times 3$ plots) for a total of 96 traps per sampling period $(24 \times 4$ habitats $)$ and a grand total of 288 traps (96 $\times 3$ sampling periods). We placed each trap flush with the ground; traps consisted of an 89-mm-diameter plastic cup filled with a mixture of soapy water, ethanol, and propylene glycol. Each trap was covered by a small plastic plate attached to three nails to limit solution evaporation and rainfall accumulation.
Leaf-litter samples were collected in July 2008 from four randomly selected stations per plot, for a total of 48 samples. One 3.79-L plastic bag of surface debris (surface materials and $\sim 2 \mathrm{~cm}$ of topsoil) was collected per station. We then sifted the debris with a mesh sheet and placed each sample in a Berlese funnel under a $40-\mathrm{W}$ bulb for $24 \mathrm{~h}$ or until the litter was completely dry. Specimens were collected in a small plastic cup filled with ethanol placed at the end of the funnel.

We thus accrued a total of 28 sampling units per plot ( 8 pitfall samples $\times 3$ trapping periods +4 leaf-litter samples $\times 1$ trapping period). Data collected over the 3 -year study period were pooled for each plot as ant composition was found to vary marginally across years (Wiescher 2010). All ants collected were identified to species (Bolton 2003; Deyrup 2003). Specimen vouchers were deposited at the University of Utah in the authors' personal collection.

\section{Species-environment relationships}

In our analysis of species-environment relationships, we evaluated only epigaeic, non-transient ant species (hereafter, full dataset). Transient ants may not have established colonies and therefore are unlikely to exhibit a meaningful habitat association (Bihn et al. 2010). A species was considered transient if it (1) occurred on no more than one plot and (2) it occurred at less than five sampling units in that plot.

To visually assess differences in assemblage composition between plots and habitat types, we used non-metric multidimensional scaling (NMDS). NMDS iteratively ranks datasets according to their pairwise dissimilarity and is well suited to data that are non-normal or on an arbitrary scale (McCune and Grace 2002). We used the total number of species incidences in sampling units to generate the ant assemblage dataset for each plot. Data were transformed with the Wisconsin double standardization and evaluated with NMDS ordination using the Kulczynski distance measure (Faith et al. 1987; Minchin 1987); random starts were utilized to select among similar solutions with the smallest amount of stress (Oksanen et al. 2009).

The correlation between environmental factors and the assemblage dataset was assessed by fitting environmental vectors onto the NMDS ordination. After calculating a goodness of fit statistic (squared correlation coefficient $r^{2}$ ), a permutation procedure (1,000 permutations) was used to define the significance of each environmental factor on all axes conjointly (Oksanen et al. 2009). Environmental factors were natural $\log (x+1)$ transformed.

To statistically evaluate if assemblage composition differed between habitats, we used multiple response permutation procedure (MRPP). MRPP is a non-parametric method that tests for significant differences between groups 
by comparing dissimilarities within and among groups (McCune and Grace 2002). We again used the total number of species incidences on plots to construct the ant assemblage dataset. We applied the Kulczynski distance measure for analysis with 1,000 permutations. All species-environment analyses were performed using R 2.10.1 (R Development Core Team 2009) with the vegan package (Oksanen et al. 2009).

\section{Species traits}

We quantified a suite of morphological characteristics for the full dataset. In the case of common species, we also quantified physiological traits: thermal tolerance and desiccation resistance. We defined common species as species interacting $>10$ times at bait resources during competition trials (Wiescher et al. 2011).

For each species, up to 8 individuals (range 4-8) were measured; in di- or polymorphic species, only minor workers were measured. Standard linear measurements were taken using an ocular micrometer on a dissecting microscope to determine species means for head width, head length, and total hind leg length (hind tibia length + hind femur length) (Kaspari and Weiser 1999; Parr et al. 2003). Relative leg length was measured as the ratio $R L=\log _{10}$ (total hind leg length +1$) \times\left[\log _{10}\right.$ (head length +1$\left.)\right]^{-1}$. To determine ant masses, we placed ants in a drying oven at $60^{\circ} \mathrm{C}$ for $24 \mathrm{~h}$ and then used a microbalance (Mettler \& Toledo( $)$ ) to weigh mean dry masses to the nearest $0.01 \mathrm{mg}$. To test for evidence of allometric relationships between ant size (head width, head length, and mass) and leg length, we performed standardized major axis regressions using the smatr package (Warton and Ormerod 2007) in R 2.10.1 (R Development Core Team 2009). Standardized major axis regressions are appropriate when testing whether the relationships between size variables differ from isometry, i.e., determining if an observed slope exhibits allometry (Warton et al. 2006). Evidence for positive allometry would consist of an observed slope of $b>1$ (for leg length vs. head width and head length) and of $b>0.33$ (for leg length vs. mass).

The thermal tolerances of common species were quantified in both field (foraging thermal limits, FTL) and laboratory (lethal temperatures, LT) settings; for a more detailed description of methods, see Wiescher et al. (2011). Briefly, we focused on heat tolerance as the subtropical climate at Archbold is characterized by hot summers and mild winters (Abrahamson 1984). Using an infrared thermometer, FTL was measured as the mean surface temperature at which species would abandon resource baits (hot dog slices) in the field. To determine LTs, we performed 10-min trials (using different ants for each trial to avoid thermal acclimation) in which growth chamber temperatures were progressively raised until $100 \%$ of ants lost locomotor control or died. LT values were calculated for each species using probit regression to estimate the temperature at which $99 \%$ of individuals succumb to heat stress; probit regression was done using R 2.10.1 (R Development Core Team 2009) and the MASS package (Venables and Ripley 2002).

Desiccation resistance was estimated for common species in the following way. We collected up to 20 individuals (range 5-20) and weighed them to the nearest $0.01 \mathrm{mg}$ to determine mean wet mass (WM). We then placed the ants in glass desiccation chambers maintained at approximately 0 relative humidity with desiccant. We defined the lethal desiccation time (LD50) as the time elapsed when $50 \%$ of ants had succumbed. Next, we weighed each species to determine the mean critical water content mass (WC). Surface areas of ants were estimated using the equation $\mathrm{SA}=0.103 \times \mathrm{WM}^{0.667}$ (Lighton and Feener 1989). Finally, we calculated area-independent water loss rates as: AIWLR $=(\mathrm{WM}-\mathrm{WC}) \times(\mathrm{LD} 50)^{-1} \times(\mathrm{SA})^{-1}$. This desiccation resistance measure enables across-species comparison by adjusting for surface area (Schilman et al. 2007). We repeated this procedure four times for each species.

For species occurring in shrub and forest habitat types, morphological measurements were determined for colonies from each habitat type; we pooled these data as preliminary analysis showed that, within species, these traits differed marginally across habitats. Two common species (Temnothorax texanus and T. pergandei) were excluded from FTL, LT, and AIWLR experiments because we could not collect sufficient foragers. These two species were among the least abundant common species (Wiescher 2010).

Trait-environment links

To simultaneously analyze the relationships between assemblage composition, species traits, and environmental variables, we used the modified fourth-corner methodology (Dray and Legendre 2008). In these analyses, a fourth-corner statistic (Pearson correlation coefficient) measures the link between species incidence at sampling units in plots, species traits, and environmental variables (groundcover, surface temperature, and VPD). Analyses were conducted on the full dataset to test links between environmental conditions and morphological traits, as well as on the dataset of common species to test links between environmental conditions and both morphological and physiological traits.

Because the physiological traits we measured are more appropriate to diurnal ants (nocturnal ants are less likely to be impacted by daytime conditions), we also analyzed the trait-environment relationship for the common species dataset weighted by diurnal activity. To generate this weighted dataset, common species incidences were multiplied by a diurnality index, calculated as the proportion of 
ant incidence at baits during the day relative to the incidence at baits during the day and at night (1 indicates species active only in daytime, 0 indicates active only at night). Baiting data (Wiescher et al. 2011) were used because pitfall trap and leaf- litter sampling did not account for activity differences between day and night. We used permutation model 2 (999 permutations) to test the significance of all relationships. Permutation model 2 tests the null hypothesis that species assemblages are randomly distributed with respect to environmental variables. The alternative hypothesis posits that species assemblages are distributed according to environmental preferences. This model is appropriate when traits and environmental variables are measured directly (fixed) and species assemblages respond to environmental gradients, as is the case here (Aubin et al. 2009; Dray and Legendre 2008). We used the Bonferroni correction procedure to account for the three environmental variables examined. Statistical analyses were done using $\mathrm{R}$ 2.10.1 (R Development Core Team 2009) with the ade4 package (Dray and Dufour 2007).

\section{Results}

Species-environment relationships

We collected 19,232 ants from pitfall traps and leaf-litter samples, totaling 48 species spanning 23 genera. Of the 48 species found, 37 species were epigaeic and non-transient (full dataset) and 18 species were common (Table 1). Common species incidences comprised $77.5 \%$ of full dataset species incidences. Both NMDS ordination and MRPP analysis showed that two distinct ant assemblages exist at Archbold: a shrub habitat assemblage (spanning Scrubby Flatwoods (SF) and Sand Pine Scrub (SP) habitats) and a forest habitat assemblage (spanning Flatwoods (FL) and Southern Ridge Sandhill (SR) habitats). NMDS ordination (dimensions $=2$, stress $=7.77$ ) indicates that the SF and SP ant assemblages strongly overlapped in ordination space. The FL and SR assemblages exhibited marginal clumping in ordination space. These two discrete groupings (SF/SP vs. FL/SR) did not exhibit overlap (Fig. 1). MRPP analysis revealed similar results. Overall, ant assemblage composition differed between the four habitats $(A=0.355$, $P=0.001)$. However, neither the SF and SP ant assemblages $(A=-0.016, P=0.511)$ nor the FL and SR ant assemblages $(A=0.165, P=0.119)$ differed statistically from each other. When grouped together, the SF/SP assemblage differed significantly from the FL/SR assemblage ( $A=0.288, P=0.002$ ). Species incidences in shrub habitat relative to forest habitat are given in Table 1.

Environmental variables differed between the shrub and forest habitats. Effect sizes for mean differences in ground-

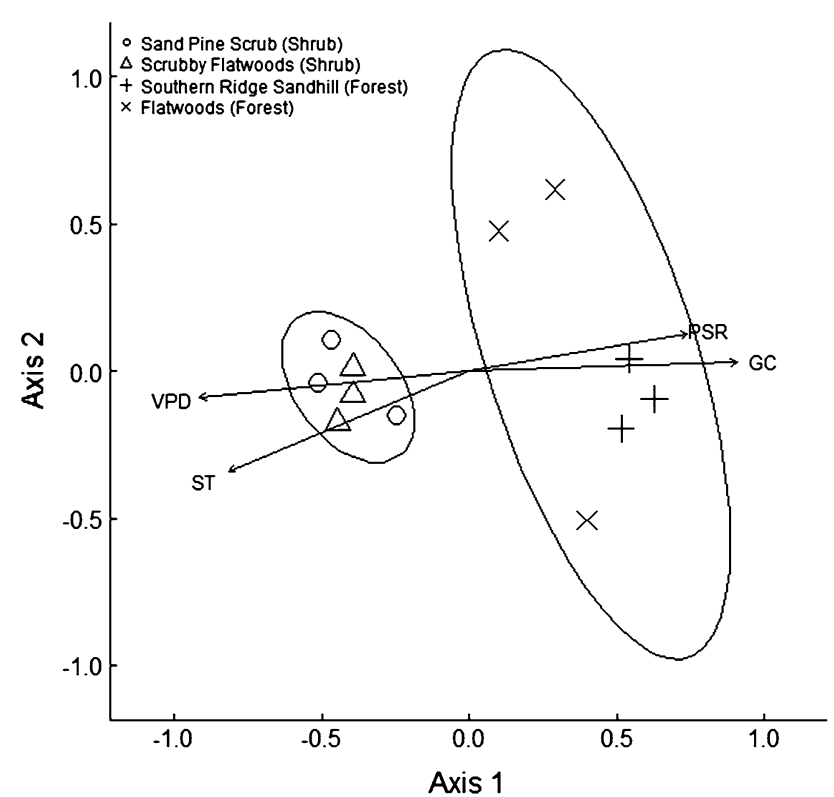

Fig. 1 NMDS ordination of ant assemblages. 95\% confidence interval ellipses for habitat types (shrub, forest) are based on the standard deviation of point scores. Environmental factors significantly correlated with NMDS ordination are shown: groundcover $(G C)$, surface temperature $(S T)$, vapor pressure deficit (VPD), and plant species richness $(P S R)$

cover, surface temperature, and VPD were pronounced: shrub habitats featured less groundcover, hotter and drier conditions, and lower plant species richness (Table 2). Furthermore, differences in ant composition were linked to a habitat's environmental conditions. Four environmental factors were significantly correlated with ant composition: groundcover $\left(r^{2}=0.90, \quad P<0.001\right)$, surface temperature $\left(r^{2}=0.86, P<0.001\right), \operatorname{VPD}\left(r^{2}=0.92, P<0.001\right)$, and plant species richness $\left(r^{2}=0.61, P=0.019\right)$ (Fig. 1). In contrast, soil moisture $\left(r^{2}=0.21, P=0.350\right)$, soil $\mathrm{pH}\left(r^{2}=0.47\right.$, $P=0.069)$, and time since fire $\left(r^{2}=0.29, P=0.209\right)$ were not significantly associated with ant composition.

Trait-environment links

A summary of species traits is given in Table 1. Leg length showed positive allometry with respect to all three measures of ant size; thus larger ants have proportionally longer leg lengths (Fig. 2). In general, certain environmental conditions were associated with leg length (Table 3). Relative leg length was negatively correlated with groundcover but positively correlated with surface temperature and VPD. This result indicates that ant species occurring in more planar and/or hotter and drier environments have relatively longer legs. In contrast, measures of ant size (dry mass, head width, or head length) were not associated with environmental conditions, showing ant assemblages tended towards similar mean size across differing habitats (Table 3). 
Table 1 Ants and their traits at Archbold Biological Station, FL

\begin{tabular}{|c|c|c|c|c|c|c|c|c|c|c|}
\hline Species & $\mathrm{HI}$ & Mass (mg) & $\mathrm{HW}(\mathrm{mm})$ & $\mathrm{HL}(\mathrm{mm})$ & $\mathrm{LL}(\mathrm{mm})$ & RL & DI & FTL $\left({ }^{\circ} \mathrm{C}\right)$ & $\mathrm{LT}\left({ }^{\circ} \mathrm{C}\right)$ & $\begin{array}{l}\text { AIWLR } \\
\left(\mathrm{mg} \times \mathrm{h}^{-1} \times \mathrm{cm}^{-2}\right)\end{array}$ \\
\hline Aphaenogaster ashmeadi* & 0.00 & 0.65 & 1.02 & 1.46 & 6.16 & 2.19 & 0.51 & 39.50 & 42.3 & 0.572 \\
\hline Brachymyrmex depilis & 0.72 & 0.02 & 0.34 & 0.37 & 0.89 & 2.02 & - & - & - & - \\
\hline Camponotus castaneus & 0.06 & 2.01 & 1.53 & 2.01 & 8.02 & 2.00 & - & - & - & - \\
\hline Camponotus floridanus* & 0.69 & 1.18 & 1.42 & 1.69 & 6.75 & 2.07 & 0.17 & 36.50 & 40.8 & 0.460 \\
\hline Camponotus socius & 0.86 & 3.07 & 1.72 & 2.16 & 10.51 & 2.12 & - & - & - & - \\
\hline Cardiocondyla emeryi & 0.62 & 0.03 & 0.34 & 0.43 & 0.98 & 1.91 & - & - & - & - \\
\hline Cyphomyrmex minutus & 0.00 & 0.12 & 0.60 & 0.65 & 1.96 & 2.17 & - & - & - & - \\
\hline Dorymyrmex bossutus & 0.30 & 0.11 & 0.62 & 0.72 & 2.82 & 2.47 & - & - & - & - \\
\hline Dorymyrmex bureni* & 0.13 & 0.11 & 0.73 & 0.85 & 3.55 & 2.46 & 0.88 & 46.50 & 47.3 & 0.283 \\
\hline Dorymyrmex elegans* & 0.96 & 0.13 & 0.75 & 0.88 & 5.11 & 2.87 & 0.62 & 45.50 & 45.2 & 0.338 \\
\hline Dorymyrmex flavopectus* & 1.00 & 0.08 & 0.73 & 0.84 & 4.06 & 2.66 & 0.80 & 45.50 & 45.6 & 0.275 \\
\hline Formica pallidefulva* & 0.28 & 0.79 & 1.16 & 1.43 & 6.76 & 2.31 & 1.00 & 44.00 & 46.9 & $0.460^{*}$ \\
\hline Forelius pruinosus* & 0.82 & 0.07 & 0.54 & 0.60 & 2.24 & 2.5 & 1.00 & 49.00 & 49.3 & 0.214 \\
\hline Hypoponera inexorata & 0.50 & 0.18 & 0.63 & 0.70 & 1.81 & 1.95 & - & - & - & - \\
\hline Hypoponera opacior & 0.54 & 0.08 & 0.51 & 0.61 & 1.47 & 1.90 & - & - & - & - \\
\hline Monomorium viride* & 0.71 & 0.03 & 0.41 & 0.50 & 1.39 & 2.15 & 1.00 & 45.75 & 47.4 & 0.124 \\
\hline Odontomachus relictus* & 0.53 & 1.46 & 1.61 & 2.03 & 6.23 & 1.78 & 0.44 & 38.50 & 41.1 & 0.273 \\
\hline Paratrechina arenivaga* & 0.79 & 0.05 & 0.47 & 0.54 & 2.10 & 2.62 & 0.37 & 37.25 & 42.8 & 0.926 \\
\hline Paratrechina phantasma & 1.00 & 0.05 & 0.50 & 0.56 & 2.21 & 2.62 & - & - & - & - \\
\hline Paratrechina wojciki* & 0.10 & 0.04 & 0.52 & 0.57 & 1.86 & 2.34 & 0.14 & 36.67 & 39.9 & 1.254 \\
\hline Pheidole adrianoi* & 1.00 & 0.03 & 0.37 & 0.41 & 1.18 & 2.27 & 0.89 & 39.50 & 44.7 & 0.467 \\
\hline Pheidole dentata* & 0.27 & 0.08 & 0.57 & 0.63 & 2.29 & 2.44 & 0.67 & 38.75 & 42.5 & 0.293 \\
\hline Pheidole floridana* & 0.05 & 0.03 & 0.42 & 0.48 & 1.27 & 2.09 & 0.61 & 39.50 & 41.7 & 0.246 \\
\hline Pheidole metallescens* & 0.72 & 0.03 & 0.44 & 0.47 & 1.30 & 2.16 & 0.81 & 40.75 & 43.7 & 0.212 \\
\hline Pheidole moerens & 0.17 & 0.03 & 0.42 & 0.45 & 1.16 & 2.07 & - & - & - & - \\
\hline Pheidole morrisii* & 0.90 & 0.09 & 0.58 & 0.70 & 2.97 & 2.6 & 0.58 & 39.50 & 41.3 & 0.264 \\
\hline Pogonomyrmex badius & 1.00 & 1.45 & 1.61 & 1.63 & 6.13 & 2.03 & - & - & - & - \\
\hline Pyramica eggersi & 0.00 & 0.03 & 0.37 & 0.35 & 0.78 & 1.92 & - & - & - & - \\
\hline Solenopsis abdita/carolinensis & 0.20 & 0.02 & 0.29 & 0.37 & 0.70 & 1.69 & - & - & - & - \\
\hline Solenopsis globularia littoralis & 0.33 & 0.04 & 0.43 & 0.52 & 1.18 & 1.86 & - & - & - & - \\
\hline Solenopsis invicta & 0.00 & 0.23 & 0.57 & 0.66 & 2.03 & 2.19 & - & - & - & - \\
\hline Solenopsis nickersoni & 0.46 & 0.02 & 0.32 & 0.37 & 0.83 & 1.92 & - & - & - & - \\
\hline Solenopsis tennesseensis & 0.59 & 0.01 & 0.25 & 0.32 & 0.53 & 1.53 & - & - & - & - \\
\hline Strumigenys emmae & 0.50 & 0.02 & 0.36 & 0.42 & 0.76 & 1.61 & - & - & - & - \\
\hline Temnothorax pergande $i^{*}$ & 0.30 & 0.11 & 0.62 & 0.74 & 1.97 & 1.97 & - & - & - & - \\
\hline Temnothorax texanus* & 1.00 & 0.13 & 0.46 & 0.60 & 1.34 & 1.81 & - & - & - & - \\
\hline Trachymyrmex septentrionalis & 0.67 & 0.41 & 1.03 & 1.02 & 3.46 & 2.13 & - & - & - & - \\
\hline
\end{tabular}

Habitat index $(H I)$ is the proportion of sampling units in which a species appeared in shrub habitats relative to all sampling units (1 indicates species only found in shrub, 0 indicates found only in forest)

Morphological measurements for all epigaeic, non-transient species include dry mass $(\mathrm{mg})$, head width $(H W)$, head length $(H L)$, leg length $(L L)$ and relative leg length $(R L)$

For common species (marked with *), the diurnality index (DI: 1 indicates species active only in daytime, 0 indicates active only at night) and physiological traits were measured: foraging thermal limit $(F T L)$, lethal temperature $(L T)$ and area-independent water loss rates (AIWLR). AIWLR for $F$. pallidefulva $(0.460 *)$ was estimated from the measure obtained for $C$. floridanus; previous work in Florida has shown these two species experience similar water loss rates (Hood and Tschinkel 1990) and are similar in size 
Table 2 Environmental characteristics of the two shrub (SS, SF) and two forest (FL, SR) habitats

\begin{tabular}{|c|c|c|c|c|c|c|c|}
\hline Habitat & $\begin{array}{l}\text { Groundcover } \\
(\%)\end{array}$ & $\begin{array}{l}\text { Surface } \\
\text { temperature }\left({ }^{\circ} \mathrm{C}\right)\end{array}$ & $\begin{array}{l}\text { Vapor pressure } \\
\text { deficit }(\mathrm{kPa})\end{array}$ & $\begin{array}{l}\text { Soil } \\
\text { moisture }(\%)\end{array}$ & $\begin{array}{l}\text { Soil } \\
\mathrm{pH}\end{array}$ & $\begin{array}{l}\text { Plant } \\
\text { diversity }\end{array}$ & $\begin{array}{l}\text { Time since } \\
\text { fire (years) }\end{array}$ \\
\hline Sand Pine Scrub (S) & 42.4 & 35.3 & 2.0 & 2.2 & 4.9 & 18.7 & 12.7 \\
\hline Scrubby Flatwoods (S) & 49.3 & 36.9 & 1.8 & 3.0 & 4.1 & 18.0 & 6.3 \\
\hline Flatwoods (F) & 90.3 & 29.9 & 1.5 & 3.3 & 4.7 & 23.7 & 11.0 \\
\hline Southern Ridge Sandhill (F) & 97.8 & 30.9 & 1.3 & 1.6 & 5.4 & 33.0 & $>40$ \\
\hline Effect size & 48.2 & 5.7 & 0.5 & 0.15 & 0.55 & 10 & $\approx 16$ \\
\hline
\end{tabular}

Surface temperature and VPD are based on summer daytime averages. Percent soil moisture, soil pH and plant diversity (species richness) are averages based on Abrahamson (1984) and Menges and Gallo (1991). Time since fire is average number of years passed using 2009 as the reference point. The mean difference between shrub $(S)$ and forest $(F)$ habitats is denoted by effect size; significant differences $(P<0.05)$ are in bold

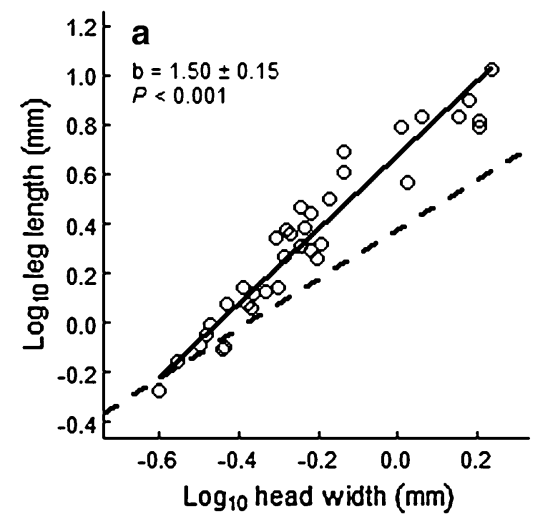

Fig. 2 Relationships between leg length (LL) and measures of ant size [head width (HW) (a); head length (HL) (b); mass (c)] for the full dataset. One-sample tests of a standardized major axis slope were performed to test for significant departures from isometry $(b=1$ for LL vs.

For the common species, we were also able to examine the relationship between their environment and physiological traits (thermal tolerance, desiccation resistance). We observed that both foraging thermal limits and lethal temperatures were negatively correlated with groundcover and positively correlated with surface temperature and VPD (Table 3). Thus, common ant species occurring in hotter and drier environments exhibit higher thermal tolerances. In contrast, desiccation resistance was not associated with the environment in which species occurred (Table 3). All these results were qualitatively unchanged when the diurnality-weighted dataset was used, although the correlation coefficients for significant relationships detected became stronger (Table 4).

\section{Discussion}

Species-environment relationships

Previous studies have found strong links between ant species and the environments in which they occur and have consequently inferred that environmental filters drive species

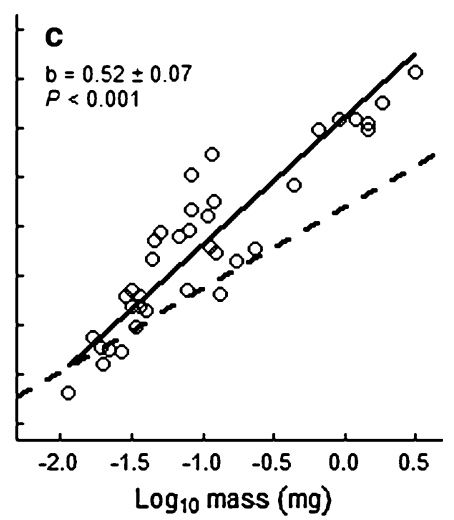

HW and HL; $b=0.33$ for LL vs. mass). The observed slope ( $b \pm \mathrm{CI})$ is shown as a solid line, the expected isometric slope as a dashed line. Associated $P$ values for the significance of the difference between observed and isometric relationships are given

habitat associations (Gotelli and Ellison 2002; Hill et al. 2008; King 2007; Sanders et al. 2007). We also report a strong association between environmental conditions and ant species, despite the high likelihood of species dispersal given the habitat mosaic. Analyses indicate that two distinct ant assemblages occur, one in the shrub habitat and one in the forest habitat. These differences in ant composition appear to be influenced by pronounced differences in surface temperature, VPD, groundcover and/or plant diversity between habitat types (Fig. 1). However, a range of other processes (e.g. competition, predation) can also generate patterns of spatial segregation, emphasizing the need to test processes underlying observed patterns (Englund et al. 2009; Gotelli and McCabe 2002; Hausdorf and Hennig 2007). To this end, we investigated the links between environmental factors and ant functional traits.

\section{Trait-environment links}

Our trait-based approach provides initial evidence that environmental filtering is a fundamental process impacting ant community assembly. Overall, the traits of ants were clearly associated with the environment in which they 
Table 3 Modified fourth-corner analysis of the correlations between species traits and environmental variables for all and common species

\begin{tabular}{lccr}
\hline Trait & $\begin{array}{l}\text { Groundcover } \\
(\%)\end{array}$ & $\begin{array}{l}\text { Surface } \\
\text { temperature }\left({ }^{\circ} \mathrm{C}\right)\end{array}$ & $\begin{array}{r}\text { VPD } \\
(\mathrm{kPa})\end{array}$ \\
\hline Full dataset & & & \\
Mass (mg) & 0.044 & -0.072 & -0.036 \\
HW (mm) & 0.033 & -0.059 & -0.027 \\
HL $(\mathrm{mm})$ & 0.048 & -0.071 & -0.038 \\
LL $(\mathrm{mm})$ & 0.023 & -0.047 & -0.010 \\
RL & $-\mathbf{0 . 2 0 8}$ & $\mathbf{0 . 1 9 8}$ & $\mathbf{0 . 1 9 8}$ \\
Common species dataset & & & \\
Mass $(\mathrm{mg})$ & 0.049 & -0.063 & -0.028 \\
HW $(\mathrm{mm})$ & 0.061 & -0.072 & -0.040 \\
HL $(\mathrm{mm})$ & 0.071 & -0.080 & -0.047 \\
LL $(\mathrm{mm})$ & 0.056 & -0.061 & -0.026 \\
RL & $-\mathbf{0 . 1 8 6}$ & $\mathbf{0 . 1 8 9}$ & $\mathbf{0 . 1 7 6}$ \\
FTL $\left({ }^{\circ} \mathrm{C}\right)$ & $-\mathbf{0 . 1 4 7}$ & $\mathbf{0 . 1 3 4}$ & $\mathbf{0 . 1 5 0}$ \\
LT $\left({ }^{\circ} \mathrm{C}\right)$ & $-\mathbf{0 . 2 0 8}$ & $\mathbf{0 . 1 8 4}$ & $\mathbf{0 . 2 1 4}$ \\
AIWLR & -0.005 & 0.004 & 0.016 \\
$\left(\mathrm{mg} \times \mathrm{h}^{-1} \times \mathrm{cm}^{-2}\right)$ & & & \\
\hline
\end{tabular}

The correlation coefficients are given; significant relationships after Bonferroni correction at $P<0.05$ are in bold. See Table 1 for abbreviations

Table 4 Modified fourth-corner analysis of correlations between species traits and environmental variables for diurnality-weighted common species dataset

\begin{tabular}{llll}
\hline Trait & $\begin{array}{l}\text { Groundcover } \\
(\%)\end{array}$ & $\begin{array}{l}\text { Surface } \\
\text { temperature }\left({ }^{\circ} \mathrm{C}\right)\end{array}$ & $\begin{array}{l}\text { VPD } \\
(\mathrm{kPa})\end{array}$ \\
\hline $\begin{array}{l}\text { Diurnality-weighted } \\
\text { dataset }\end{array}$ & & & \\
FTL $\left({ }^{\circ} \mathrm{C}\right)$ & $\mathbf{- 0 . 2 0 6}$ & $\mathbf{0 . 1 6 8}$ & $\mathbf{0 . 2 1 2}$ \\
LT $\left({ }^{\circ} \mathrm{C}\right)$ & $\mathbf{- 0 . 2 5 1}$ & $\mathbf{0 . 2 0 6}$ & $\mathbf{0 . 2 5 7}$ \\
AIWLR & -0.006 & 0.009 & 0.027 \\
$\left(\mathrm{mg} \times \mathrm{h}^{-1} \times \mathrm{cm}^{-2}\right)$ & & & \\
\hline
\end{tabular}

The correlation coefficients are given; significant relationships after Bonferroni correction at $P<0.05$ are in bold. See Table 1 for abbreviations and diurnality index

occurred. We found mixed support for the size-grain hypothesis (Kaspari and Weiser 1999), which makes the prediction that ants in planar environments should have relatively longer legs and be larger than ants in more complex environments. Like Parr et al. (2003), we found no evidence that body sizes differ along a ground complexity gradient (Table 3), suggesting they do not explain the habitat associations we observed. We did, however, find evidence for increasing relative leg length with decreasing groundcover (Table 3). Because mean ant size is not greater in more planar habitats, this pattern is not an allometric artifact driven by more large, and therefore longer-legged
(Fig. 2), ants occurring in planar habitats, but instead it implies that there is an ecological advantage to relative leg length given certain environmental conditions. Relatively longer legs may enable species foraging on top of leaf litter or on planar surfaces to discover food resources more quickly (Farji-Brener et al. 2004; Pearce-Duvet et al. 2011a), while the advantage goes to shorter-legged species in more complex habitats (Farji-Brener et al. 2004). In addition, because comparatively low plant diversity in planar shrub habitat (Table 2) could result in lower plantderived resource availability for ants, the advantage for longer-legged species better at discovery may be further amplified (Pearce-Duvet et al. 2011b).

An alternative explanation is thermal constraints drive assemblage-wide differences in relative leg length. The greater surface temperatures and VPD in the sandy soil shrub habitats (Table 3 ) could promote relatively longer legs as they increase the distance between an ant's body and the heat-radiating soil (Cerdá 2001; Cerdá and Retana 2000). However, we found no relationship between relative leg lengths and foraging thermal limits $\left(F_{1,14}=2.58\right.$, $\left.P=0.130, R^{2}=0.10\right)$ or lethal temperatures $\left(F_{1,14}=1.71\right.$, $\left.P=0.212, R^{2}=0.05\right)$ in common species, showing that leg morphology is not associated with greater thermal tolerance at Archbold. In addition, the correlation coefficient describing the link between relative leg length and groundcover was stronger than the links between relative leg length and surface temperature or VPD (Table 3). Consequently, we feel leg length patterns are best explained by groundcover complexity, as per the size-grain hypothesis (Kaspari and Weiser 1999).

Heat tolerance also appears to be important in determining habitat associations. For the common species, thermal tolerance in the field (foraging thermal limits) and in the laboratory (lethal temperatures) were both positively associated with increasing surface temperatures and VPD (Table 3). Although ground-nesting species can easily seek refuge from the extreme soil temperatures $\left(>40^{\circ} \mathrm{C}\right)$ attained in shrub habitats, the regularity at which the exposed sandy soils reach those temperatures in summer and even winter months may considerably shorten the foraging time available to diurnal species (Wiescher et al. 2011). Heat-intolerant species may have a relatively harder time acquiring food in shrub habitats, and thus their abundance may be more limited. For example, heat-tolerant Forelius pruinosus and Dorymyrmex species tend to be more abundant in arid shrub habitat while the heat-intolerant Pheidole floridana is more abundant in the forest (Table 1).

While previous studies have inferred that species distributions are driven by temperature at broader (Jenkins et al. 2011; Kaspari et al. 2000a, b; Lessard et al. 2010) and finer (Bestelmeyer 1997; Retana and Cerdá 2000; Spiesman and Cumming 2008) geographic scales, or shown that species 
activity patterns are mediated by temperature (Albrecht and Gotelli 2001; Cros et al. 1997; Lessard et al. 2009), our results are the first, to our knowledge, to show a direct link between distribution patterns and species' thermal traits at the regional scale. Not surprisingly, temperature-mediated habitat associations may be particularly relevant for diurnal species, as the positive relationship between thermal traits and surface temperatures/VPD in the diurnality-weighted dataset was considerably stronger (higher correlation coefficients) (Table 4) than in the unweighted dataset (Table 3). This result is driven by the strong positive relationship between diurnality and both foraging thermal limits $\left(F_{1,14}=23.45, P<0.001, R^{2}=0.60\right)$ and lethal temperatures $\left(F_{1,14}=43.84, \quad P<0.001, \quad R^{2}=0.74\right) \quad$ which shows that thermal tolerances may not only constrain where, but also when, species can effectively forage for resources.

Desiccation resistance has the potential to shape assemblage composition as water loss tolerance can affect the distribution of individual species and arboreal assemblages (Hood and Tschinkel 1990; Lighton and Feener 1989; Menke and Holway 2006). However, it appears to be of limited importance to shaping habitat associations of the epigaeic assemblage studied here. We found that species in the arid shrub did not retain water more effectively than those in the mesic forest (Table 3). Furthermore, even though diurnal species are predicted to be more affected by high daytime VPD, the diurnality-weighted analysis also showed no correlation between desiccation resistance and VPD (Table 4). While several species active during high VPD conditions (especially diurnal shrub species such as $F$. pruinosus, $M$. viride, and Dorymyrmex species) do exhibit high desiccation resistance, diurnal species abundant in the comparatively low VPD forest, such as Pheidole dentata and $P$. floridana, are similarly resistant (Table 1). Instead, desiccation resistance may be a standard and necessary trait for ants active during daytime VPD conditions in this region, regardless of their habitat. Interestingly, primarily nocturnal species (e.g., Camponotus floridanus and Paratrechina species) that forage in the extremely humid conditions of Florida's nighttime have low desiccation resistance (Table 1), suggesting desiccation resistance may influence diel activity patterns, i.e., when species forage rather than where species occur.

While the traits of shrub ant species can explain their persistence in low complexity and hot habitats, it is unclear what limits their occurrence in the more moderate, complex forests. Resource competition may act in conjunction with trait-environment constraints to ultimately determine habitat associations among ants. In African ant acacia assemblages, competitive dominants appear to exclude subordinates from trees in highly productive areas; subordinates persist on trees in areas of low productivity because they exhibit greater stress tolerance than competitive dominants (Palmer 2003). In a Mediterranean ant assemblage, dominant species are more abundant in forests and may exclude subordinate species from these habitats, while subordinates thrive instead in arid open areas (Cerdá et al. 1998b; Retana and Cerdá 2000). It may be that competitive pressures in the more productive forest habitat at Archbold (S. Sonali, unpublished data) are fiercer and limit the persistence of behaviorally subordinate shrub-associated species. At Archbold, local species interactions can also strongly influence ant coexistence (Wiescher et al. 2011), and thus the links documented here should be viewed as an important but insufficient proximate determinant of local community composition. Indeed, studies in other systems suggest filtering occurs in conjunction with other determinant factors. For instance, a study examining coastal fish communities reveals both predation and species tolerance to low oxygen determine differing species assemblages along water depth and oxygen gradients (Englund et al. 2009). The relative importance of the different factors simultaneously affecting ant coexistence at regional scales clearly invites further investigation.

A primary aim of ecology is to delimit the processes governing how species assemblages and their functional traits vary across environmental gradients (McGill et al. 2006). Using extensive data on environmental conditions, species composition, and species traits collected in a subtropical ant assemblage, we provide one of the first examples of mechanistic support for the process of environmental filtering in determining ant assemblage composition. In particular, our assemblages appeared to be framed by differences in broader habitat conditions (open, hot shrub and complex, mesic forest) and a species' traits were distinctly suited to the habitat in which that species occurred. Although plant diversity also differs between habitats and could indirectly affect ant-habitat associations via differences in resource availability, epigaeic ants appear to be predominantly opportunistic and omnivorous feeders (Gibb and Cunningham 2011; Wiescher 2010), and thus should be minimally affected. However, while filtering appears to explain an important part of habitat associations, it does not explain the absence of shrub-suited species in forest habitats. Rather, environmental filters likely act in conjunction with local competitive pressures to ultimately parse the regional species pool into its respective local pools.

Finally, our results strongly support the notion that ant physiology, especially thermal tolerance, will impact ant assemblages experiencing climate change. Our work responds to a need for studies on physiological traits, especially thermal tolerance and desiccation resistance, and how they shape ant assemblages in hotter regions (Jenkins et al. 2011); developing this understanding is pressing, given that climate models predict the expansion of extreme climate 
habitats. Climate warming could shift ant assemblage composition in currently moderate environments away from heat-intolerant species and towards heat-tolerant species. Another consequence may be that comparatively thermally intolerant diurnal species have to become more nocturnal, which could result in intensified competitive pressures at night and subsequent reductions in ant diversity. In either scenario, warming regimes may initiate compositional changes and determining thermal physiology of ecologically important ant species will be essential to predicting ecosystem changes, especially in regions expected to undergo strong warming.

Acknowledgments We thank Mark Deyrup for help identifying species, discussing results and sharing laboratory space. A. Briles, J. Barnett, A. Lee-Bibo, and R. Gurr provided assistance in the field and with sample sorting. Comments by Phil Lester and two anonymous reviewers improved the manuscript. This work was supported by Archbold Biological Station graduate research internships and a NSF GK-12 Fellowship to P.T. Wiescher, a NSF Pre-doctoral Fellowship and International Postdoctoral Research Fellowship to J.M.C. Pearce-Duvet, and NSF Grants DEB-0316524 and DGE-0841233 to D.H. Feener, Jr.

Conflict of interest The authors declare that they have no conflicts of interest.

\section{References}

Abrahamson WG (1984) Vegetation of the Archbold Biological Station, Florida: an example of the southern Lake Wales Ridge. Fla Sci 47:209-250

Agrawal AA, Ackerly DD, Adler F, Arnold AE, Caceres C, Doak DF, Post E, Hudson PJ, Maron J, Mooney KA, Power M, Schemske D, Stachowicz J, Strauss S, Turner MG, Werner E (2007) Filling key gaps in population and community ecology. Front Ecol Environ 5:145-152. doi:10.1890/1540-9295(2007)5[145:FKGIPA]2.0.CO;2

Albrecht M, Gotelli NJ (2001) Spatial and temporal niche partitioning in grassland ants. Oecologia 126:134-141. doi:10.1007/ s004420000494

Aubin I, Ouellette M-H, Legendre P, Messier C, Bouchard A (2009) Comparison of two plant functional approaches to evaluate natural restoration along an old-field-deciduous forest chronosequence. J Veg Sci 20:185-198. doi:10.1111/j.1654-1103.2009. 05513.x

Bestelmeyer BT (1997) Stress tolerance in some Chacoan dolichoderine ants: implications for community organization and distribution. J Arid Environ 35:297-310. doi:10.1006/jare.1996.0147

Bestelmeyer BT (2000) The trade-off between thermal tolerance and behavioural dominance in a subtropical South American ant community. J Anim Ecol 69:998-1009. doi:10.1046/j.1365-2656. 2000.00455.x

Bestelmeyer BT, Agosti D, Alonso LE, Brandão CRF, Brown WL Jr, Delabie JHC, Silvestre R (2000) Field techniques for the study of ground-dwelling ants: an overview, description and evaluation. In: Agosti D, Majer J, Alonso LE, Schultz T (eds) Ants: standard methods for measuring and monitoring biodiversity. Smithsonian Institution Press, Washington, DC, pp 122-144

Bihn JH, Gebauer G, Brandl R (2010) Loss of functional diversity of ant assemblages in secondary tropical forests. Ecology 91:782792. doi:10.1890/08-1276.1
Bolton B (2003) Synopsis and classification of Formicidae. Mem Am Entomol Inst 71:1-370

Cerdá X (2001) Behavioural and physiological traits to thermal stress tolerance in two Spanish desert ants. Etologiá 9:15-27

Cerdá X, Retana J (2000) Alternative strategies by thermophilic ants to cope with extreme heat: individual versus colony level traits. Oikos 89:155-163. doi:10.1034/j.1600-0706.2000.890117.x

Cerdá X, Retana J, Cros S (1998a) Critical thermal limits in Mediterranean ant species: trade-off between mortality risk and foraging performance. Funct Ecol 12:45-55. doi:10.1046/j.1365-2435.1998. 00160.x

Cerdá X, Retana J, Manzaneda A (1998b) The role of competition by dominants and temperature in the foraging of subordinate species in Mediterranean ant communities. Oecologia 117:404-412. doi: $10.1007 / \mathrm{s} 004420050674$

Cros S, Cerda X, Retana J (1997) Spatial and temporal variations in the activity patterns of Mediterranean ant communities. Ecoscience 4:269-278

Deyrup M (2003) An updated list of Florida ants (Hymenoptera: Formicidae). Fla Entomol 86:43-48. doi:10.1653/0015-4040(2003) 086[0043:AULOFA]2.0.CO;2

Deyrup M, Trager J (1986) Ants of the Archbold Biological Station, Highlands County, Florida (Hymenoptera: Formicidae). Fla Entomol 69:206-228

Doblas-Miranda E, Reyes-Lopez J (2008) Foraging strategy quick response to temperature of Messor barbarus (Hymenoptera: Formicidae) in Mediterranean environments. Environ Entomol 37:857861. doi:10.1603/0046-225x(2008)37[857:fsqrtt]2.0.co;2

Dray S, Dufour AB (2007) The ade4 package: implementing the duality diagram for ecologists. J Stat Software 22:1-20

Dray S, Legendre P (2008) Testing the species traits-environment relationships: the fourth-corner problem revisited. Ecology 89:34003412. http://www.jstor.org/stable/27650916

Englund G, Johansson F, Olofsson P, Salonsaari J, Ohman J (2009) Predation leads to assembly rules in fragmented fish communities. Ecol Lett 12:663-671. doi:10.1111/j.1461-0248.2009.01322.x

Faith DP, Minchin PR, Belbin L (1987) Compositional dissimilarity as a robust measure of ecological distance. Plant Ecol 69:57-68. doi:10.1007/bf00038687

Farji-Brener AG, Barrantes G, Ruggiero A (2004) Environmental rugosity, body size and access to food: a test of the size-grain hypothesis in tropical litter ants. Oikos 104:165-171. doi:10.1111/ j.0030-1299.2004.12740.x

Folgarait PJ (1998) Ant biodiversity and its relationship to ecosystem functioning: a review. Biodivers Conserv 7:1221-1244. doi:10.1023/ A:1008891901953

Gibb H, Cunningham SA (2011) Habitat contrasts reveal a shift in the trophic position of ant assemblages. J Anim Ecol 80:119-127. doi:10.1111/j.1365-2656.2010.01747.x

Gotelli NJ, Ellison AM (2002) Assembly rules for New England ant assemblages. Oikos 99:591-599. doi:10.1034/j.1600-0706.2002. 11734.x

Gotelli NJ, McCabe DJ (2002) Species co-occurrence: a meta-analysis of JM Diamond's assembly rules model. Ecology 83:2091-2096. doi:10.1890/0012-9658(2002)083[2091:SCOAMA]2.0.CO;2

Green JL, Bohannan BJM, Whitaker RJ (2008) Microbial biogeography: from taxonomy to traits. Science 320:1039-1043. doi:10.1126/ science. 1153475

Hausdorf B, Hennig C (2007) Null model tests of clustering of species, negative co-occurrence patterns and nestedness in meta-communities. Oikos 116:818-828. doi:10.1111/j.0030-1299.2007.15661.x

Hill JG, Summerville KS, Brown RL (2008) Habitat associations of ant species (Hymenoptera: Formicidae) in a heterogeneous Mississippi landscape. Environ Entomol 37:453-463. doi:10.1603/ 0046-225x(2008)37[453:haoash]2.0.co;2 
Hölldobler B, Wilson EO (1990) The ants. Harvard University Press, Cambridge

Hood WG, Tschinkel WR (1990) Desiccation resistance in arboreal and terrestrial ants. Physiol Entomol 15:23-25. doi:10.1111/ j.1365-3032.1990.tb00489.x

Jenkins CN, Sanders NJ, Andersen AN, Arnan X, Brühl CA, Cerda X, Ellison AM, Fisher BL, Fitzpatrick MC, Gotelli NJ, Gove AD, Guénard B, Lattke JE, Lessard J-P, McGlynn TP, Menke SB, Parr CL, Philpott SM, Vasconcelos HL, Weiser MD, Dunn RR (2011) Global diversity in light of climate change: the case of ants. Divers Distrib 17:652-662. doi:10.1111/j.1472-4642.2011.00770.x

Kaspari M (1993) Body size and microclimate use in Neotropical granivorous ants. Oecologia 96:500-507. doi:10.1007/BF00320507

Kaspari M, Weiser MD (1999) The size-grain hypothesis and interspecific scaling in ants. Funct Ecol 13:530-538. doi:10.1046/j.13652435.1999.00343. $\mathrm{x}$

Kaspari M, Weiser MD (2000) Ant activity along moisture gradients in a neotropical forest. Biotropica 32:703-711. doi:10.1111/j.17447429.2000.tb00518.x

Kaspari M, Alonso L, O'Donnell S (2000a) Three energy variables predict ant abundance at a geographical scale. Proc R Soc Lond B 267:485-489. doi:10.1098/rspb.2000.1026

Kaspari M, O'Donnell S, Kercher JR (2000b) Energy, density, and constraints to species richness: ant assemblages along a productivity gradient. Am Nat 155:280-293. doi:10.1086/303313

Keddy P (1992) Assembly and response rules: two goals for predictive community ecology. J Veg Sci 3:157-164. doi:10.2307/3235676

King JR (2007) Patterns of co-occurrence and body size overlap among ants in Florida's upland ecosystems. Ann Zool Fenn 44:189-201

Lavorel S, Garnier E (2002) Predicting changes in community composition and ecosystem functioning from plant traits: revisiting the Holy Grail. Funct Ecol 16:545-556. doi:10.1046/j.1365-2435.2002.00664.x

Lebrija-Trejos E, Pérez-García EA, Meave JA, Bongers F, Poorter L (2010) Functional traits and environmental filtering drive community assembly in a species-rich tropical system. Ecology 91:386-398. doi:10.1890/08-1449.1

Lessard JP, Dunn RR, Sanders NJ (2009) Temperature-mediated coexistence in temperate forest ant communities. Insectes Soc 56:149 156. doi:10.1007/s00040-009-0006-4

Lessard JP, Sackett TE, Reynolds WN, Fowler DA, Sanders NJ (2010) Determinants of the detrital arthropod community structure: the effects of temperature and resources along an environmental gradient. Oikos 120:333-343. doi:10.1111/j.1600-0706.2010.18772.x:1-11

Lighton JRB, Feener DH Jr (1989) Water-loss rate and cuticular permeability in foragers of the desert ant Pogonomyrmex rugosus. Physiol Zool 62:1232-1256

McCune B, Grace JB (2002) Analysis of ecological communities. MjM Software Design, Gleneden Beach

McGill BJ, Enquist BJ, Weiher E, Westoby M (2006) Rebuilding community ecology from functional traits. Funct Ecol 21:178-185. doi:10.1016/j.tree.2006.02.002

Menezes S, Baird DJ, Soares AMVM (2010) Beyond taxonomy: a review of macroinvertebrate trait-based community descriptors as tools for freshwater biomonitoring. J Appl Ecol 47:711-719. doi:10.1111/j.1365-2664.2010.01819.x

Menges ES, Gallo NP (1991) Water relations of scrub oaks on the Lake Wales Ridge, Florida. Fla Sci 54:69-79

Menges ES, Abrahamson WG, Givens KT, Gallo NP, Layne JN (1993) Twenty years of vegetation change in five long-unburned Florida plant communities. J Veg Sci 4:375-386. doi:10.2307/3235596

Menke SB, Holway DA (2006) Abiotic factors control invasion by Argentine ants at the community scale. J Anim Ecol 75:368-376. doi:10.1111/j.1365-2656.2006.01056.x
Minchin PR (1987) An evaluation of the relative robustness of techniques for ecological ordination. Plant Ecol 69:89-107. doi:10.1007/bf00038690

Oksanen J, Kindt R, Legendre P, O’Hara B, Simpson GL, Solymos P, Henry H, Stevens H, Wagner H (2009) Vegan: community ecology package. $\mathrm{R}$ package version $1.15-2$

Palmer TM (2003) Spatial habitat heterogeneity influences competition and coexistence in an African acacia ant guild. Ecology 84:2843-2855. doi:10.1890/02-0528

Parr ZJE, Parr CL, Chown SL (2003) The size-grain hypothesis: a phylogenetic and field test. Ecol Entomol 28:475-481. doi:10.1046/ j.1365-2311.2003.00529.x

Pearce-Duvet JMC, Elemans CPH, Feener DH Jr (2011a) Walking the line: search behavior and foraging success in ant species. Behav Ecol 22:501-509. doi:10.1093/beheco/arr001

Pearce-Duvet JMC, Moyano M, Adler FR, Feener DH Jr (2011b) Fast food in ant communities: how competing species find resources. Oecologia 167:229-240. doi:10.1007/s00442-011-1982-4

R Development Core Team (2009) R: A language and environment for statistical computing. 2.10.1 edn. R Foundation for Statistical Computing, Vienna

Retana J, Cerdá X (2000) Patterns of diversity and composition of Mediterranean ground ant communities tracking spatial and temporal variability in the thermal environment. Oecologia 123:436444. doi: $10.1007 / \mathrm{s} 004420051031$

Sanders NJ, Gotelli NJ, Wittman SE, Ratchford JS, Ellison AM, Jules ES (2007) Assembly rules of ground-foraging ant assemblages are contingent on disturbance, habitat and spatial scale. J Biogeogr 34:1632-1641. doi:10.1111/j.1365-2699.2007.01714.x

Sarty M, Abbott KL, Lester PJ (2006) Habitat complexity facilitates coexistence in a tropical ant community. Oecologia 149:465-473. doi:10.1007/s00442-006-0453-9

Schilman PE, Lighton JRB, Holway DA (2007) Water balance in the Argentine ant (Linepithema humile) compared with five common native ant species from southern California. Physiol Entomol 32:1-7. doi:10.1111/j.1365-3032.2006.00533.x

Southwood TRE (1988) Tactics, strategies and templets. Oikos 52:3-18

Spiesman BJ, Cumming GS (2008) Communities in context: the influences of multiscale environmental variation on local ant community structure. Landsc Ecol 23:313-325. doi:10.1007/ s10980-007-9186-3

van Ingen LT, Campos RI, Andersen AN (2008) Ant community structure along an extended rain forest-savanna gradient in tropical Australia. J Trop Ecol 24:445-455. doi:10.1017/S026646740 8005166

Venables WN, Ripley BD (2002) Modern applied statistics with S, 4th edn. Springer, New York

Ward AD, Elliot WJ (1995) Environmental hydrology. Lewis, Boca Raton

Warton DI, Ormerod J (2007) Smatr: (standardised) major axis estimation and testing routines. $\mathrm{R}$ package version 2.1

Warton DI, Wright IJ, Falster DS, Westoby M (2006) Bivariate linefitting methods for allometry. Biol Rev 81:259-291. doi:10.1017/ S1464793106007007

Webb CT, Hoeting JA, Ames GM, Pyne MI, Poff NL (2010) A structured and dynamic framework to advance traits-based theory and prediction in ecology. Ecol Lett 13:267-283. doi:10.1111/j.14610248.2010.01444.x

Weiher E, Keddy P (1999) Ecological assembly rules: perspectives, advances, retreats. Cambridge University Press, New York

Wiescher PT (2010) Ant coexistence in a spatially heterogeneous region in central Florida. PhD dissertation, University of Utah, Salt Lake City 
Wiescher PT, Pearce-Duvet JMC, Feener DH Jr (2011) Environmental context alters ecological trade-offs controlling ant coexistence in a spatially heterogeneous region. Ecol Entomol 36:549-559. doi:10.1111/j.1365-2311.2011.01301.x
Wittman SE, Sanders NJ, Ellison AM, Jules ES, Ratchford JS, Gotelli NJ (2010) Species interactions and thermal constraints on ant community structure. Oikos 119:551-559. doi:10.1111/j.16000706.2009.17792.x 